\title{
Effect of Lime Application to Acidic Soils on Oleoresin Yield Tapped from Pine Plantations in South China
}

\author{
Run-Peng Wei ${ }^{1,2^{*}}$, Ruchun Yang ${ }^{3}$, Qiaowen Wei ${ }^{4}$ \\ ${ }^{1}$ Forestry College, South China Agricultural University, Guangzhou, China \\ ${ }^{2}$ Weirptech Bioresources Limited, Hong Kong, China \\ ${ }^{3}$ Yunfu Chengda Chemical Rosin Co. Ltd., Yunfu, China \\ ${ }^{4}$ Sino-Biotechnology (Guangzhou) Ltd., Guangzhou, China \\ Email: *weirunpeng@yahoo.com.hk
}

Received 29 April 2014; revised 17 June 2014; accepted 30 June 2014

Copyright (C) 2014 by authors and Scientific Research Publishing Inc.

This work is licensed under the Creative Commons Attribution International License (CC BY).

http://creativecommons.org/licenses/by/4.0/

(c) (i) Open Access

\section{Abstract}

Oleoresin is a major non-forest product collected from commercially mature or near mature pine trees. Efforts have been made to increase oleoresin yield, but basically limited to the genetic improvement of planting materials and the application of chemical stimulants to tapping surface of trees. Nutrition management may play a role, particularly for pine stands suffering from soil acidification and degradation. We set up a field experiment including application of water retainer, NPK complex fertilizer, lime and borax in different combinations to pine stands for oleoresin tapping with extremely low soil $\mathrm{pH}$ value and nutrition. Lime significantly affected the annual yield of oleoresin tapped from two pine species studied $(P<0.05)$. Among 3 levels of lime applied $(0,100$, $200 \mathrm{~g} /$ tree), the oleoresin yield increased as the dose increased in slash pine, but was highest at $100 \mathrm{~g} /$ tree in masson pine. The doses of $167 \mathrm{~g}$ and $133 \mathrm{~g}$ of lime per tree were optimal or close to be optimal for slash pine and masson pine, respectively. The effects of other three matters applied were statistically insignificant $(P>0.10)$. In addition, all of the four matters applied did not influence the growth of both pine species. We concluded that proper use of lime alone may generate $15 \%$ to $35 \%$ of gain in oleoresin production for pine plantations with similar soil conditions in the region. We also discussed the potential of comprehensive soil or site management, and proposed further research for improvement of pine oleoresin production.

\section{Keywords}

Pine, Acidic Soil, Lime, Oleoresin Production, Site Management

\footnotetext{
${ }^{*}$ Corresponding author.
} 


\section{Introduction}

Several pine species greatly contribute to both wood fiber and oleoresin production, such as, Pinus massoniana Lamb. (masson pine), P. elliottii Engelm. (slash pine), P. latteri Mason, P. yunnanensis Franch etc., in the South China (Wei, 1990; Coppen \& Hone, 1995; Song, 1998; Chen \& Li, 2009). Oleoresin is usually tapped as a sideproduct from economically mature or near-mature stands for some years before timber is finally clear-cut. In less than one decade, such "side-product" has become parallel with or even more weighted than wood product in terms of economic value mainly due to the rising market demand and the reduced pine forest resources.

There exist means to increase oleoresin yield. For long-term purpose, newly planting of genetically improved material is very effective as the heritability of oleoresin yield is much higher than that of wood growth (McReynolds, 1971; Lu et al., 1992; Roberds \& Strom, 2006). However, it may take at least 15 years before the new planting becomes mature for tapping. For the existing mature stands, research and practice have been focused on application of chemical stimulants to tapping surface (Liu \& Zhu, 2003; Chen, 2004; Liu et al., 2007; Rodrigues et al., 2008; Chen \& Li, 2009). Site or soil nutrition management during oleoresin tapping period hardly attracts attention, considering cost and slow growth rate or stand age close to final clear-cut. Some studies reported the effects of fertilizing on the growth along with oleoresin yield of medium-age or near mature pine stands, but the conclusions appeared confusing and inconsistent (Warren et al., 1999; Knebel et al., 2008; Xie, 2008; Shu et al., 2009; An et al., 2010).

Oleoresin yield depends on tree size, vigor, physiological activity and root-associated myccorhizae, which is closely related to soil physical and chemical properties including $\mathrm{pH}$ value, available nutrition, moisture, etc. (Lorio \& Sommers, 1986; Rigling et al., 2003; Rodrigues et al., 2008; Chen \& Li, 2009; Rodríguez-García et al., 2014). It could be expected therefore that change in soil physical and chemical properties plays a role in producing pine oleoresin. In the present study, we investigated the effects of several soil treatment materials, and the potential economic benefit of their effective application. In addition, we also discussed the concept of site or soil management for oleoresin production from economically mature or near-mature pine stands.

\section{Materials and Methods}

\subsection{Species}

Two main pine species for oleoresin production were included in the present study, i.e., masson pine ( $P$. massoniana Lamb.), a most widely distributed and planted native in the South China (Song, 1998; Chen \& Li, 2009), and slash pine (P. elliottii Engelm.), a southeastern US origin and world-wide introduced and planted exotic (Wei, 1990). In 1980s and early 1990s, both pines were once the most important species for reforestation and commercial plantation development in the South China (Wei, 1990).

\subsection{Stands and Soil Nutrition Status}

The field experiment was located at Silao, Yunfu of the Center-West Guangdong, a typical region characterized as pine oleoresin production for a long history (Chen \& Li, 2009). One masson pine stand (lat 22 ${ }^{\circ} 56^{\prime} 15.8^{\prime \prime} \mathrm{N}$, long $112^{\circ} 14 ' 32.9^{\prime \prime} \mathrm{E}$ and alt $87 \mathrm{~m}$ ) at 25-year old and another nearby slash pine stand (lat $22^{\circ} 56^{\prime} 15.2^{\prime \prime} \mathrm{N}$, long $112^{\circ} 14^{\prime} 22.3^{\prime \prime} \mathrm{E}$ and alt $85 \mathrm{~m}$ ) at 20-year old were selected for setting up this field experiment. They were initially planted at a spacing of 3 (row) $\times 2.22$ (tree) m or a density of 1500 trees/ha, and thinned to about 1050 trees/ha at 10-year old. Both stands performed normal with similar tree conditions such as growing status and oleoresin tapping as most of other pine plantations or forests in the South China. Besides, both stands had same or similar climate and site conditions.

By following the national standardized method (NSSO, 1992), soil samples were collected and tested in laboratory to evaluate soil properties or nutrition status for the corresponding experiment sites of two stands (Table 1). Belonging to red earth or ultisol, the soil was extremely acid ( $\mathrm{pH}$ value $<4.0$ ) for both pine stands, mainly due to acid deposition (Zhou \& Qin, 1992; Liu, 2007) and land degradation caused by long term human disturbance (Li et al., 2003). According to the national criteria (NSSO, 1992), the soil organic matter content was slightly above medium for slash pine stand but was low for masson pine; the total soil $\mathrm{N}$ and $\mathrm{P}$ were extremely low for both species; the total $\mathrm{K}$ was medium for masson pine but low for slash pine. The available $\mathrm{N}$ and $\mathrm{K}$ were low, and available $\mathrm{P}$ was extremely low for both species. Obviously, the soil nutrition status was unexpectedly acid and poor. 
Table 1. Soil nutrition status of the experimental sites for both species.

\begin{tabular}{ccccc}
\hline Species & pH-value & Organic matter $(\mathrm{g} / \mathrm{kg})$ & Total N $(\mathrm{g} / \mathrm{kg})$ & Total P $(\mathrm{g} / \mathrm{kg})$ \\
\hline Slash pine & 3.96 & 30.50 & 0.06 & 0.25 \\
Masson pine & 3.85 & 17.19 & 0.09 & 0.37 \\
Species & Total K $(\mathrm{g} / \mathrm{kg})$ & Available N $(\mathrm{mg} / \mathrm{kg})$ & Available P $(\mathrm{mg} / \mathrm{kg})$ & Available K $(\mathrm{mg} / \mathrm{kg})$ \\
Slash pine & 8.22 & 53.74 & 1.10 & 25.43 \\
Masson pine & 15.87 & 44.27 & 1.01 & 32.07 \\
\hline
\end{tabular}

\subsection{Soil Treatment Materials and Experimental Design}

Four soil nutrition or amendment materials were included in the experiment: 1) NPK complex fertilizer (N:P:K $=15: 15: 15)$ (Yara, Norway), denoted as $\mathrm{C}$; 2) 100-mess lime or calcium hydroxide $\left(\mathrm{Ca}(\mathrm{OH})_{2}\right)$ (Guangyu, Guangdong, China), L; 3) borax (Xingpeng, Liaoning, China), B; and 4) water retainer, Aquasorb 3005KM (SNF, France), W. Choice of the first three materials were based on the consideration of the status of soils with poor nutrition, extreme acidity and deficient $\mathrm{B}$ at the experiment sites as well as over the wide-range of forestlands in the South China (Liu et al., 1982; Zhou \& Qin, 1992; Li et al., 2003; Liu, 2007). Inclusion of water retainer aimed to improve soil moisture evenness around the tapped trees during the oleoresin tapping season. An orthogonal design $\left(\mathrm{L}_{9}\left(3^{4}\right)\right)$ with four factors (materials), each of three levels, was adopted to generate nine soil treatment schemes (Table 2). Four materials for each scheme and each tree were weighted, mixed and wrapped in kraft paper before applied to the experimental trees.

For each species, a piece (about $1500 \mathrm{~m}^{2}$ ) of land with representative trees was selected for the field experiment, which was divided into two blocks (replicates) separately sitting in the lower and upper parts, respectively, of the hill slopes. Along the contour or tree row direction, each block was further divided into 9 plots, each of six rows of trees and two trees per row initially planted $(18 \times 4.44 \mathrm{~m})$. Within each plot, 4 largest and normal trees ( 5 trees each plot for one block of masson pine) were selected and marked as the experimental trees. By adopting complete random block design for the field experiment, 9 soil treatment schemes (T1 to T9) were randomly allocated to these plots within each block. In total, there were $72(=2 \times 9 \times 4)$ and $81(=1 \times 9 \times 4+1 \times 9$ $\times 5$ ) experimental trees for slash pine and masson pine, respectively. On April 15, 2009 before oleoresin tapping, the pre-prepared nutrition or amendment material mixtures were applied to pre-dug horizontal ditches $(120 \mathrm{~cm}$ length $\times 30 \mathrm{~cm}$ width $\times 30 \mathrm{~cm}$ depth) in the upper side (about 1 meter distance) of the corresponding experimental trees, well mixed with soil to $1 / 3$ of ditch, and fully filled with topsoil.

\subsection{Tree Measurement and Oleoresin Tapping}

Before applying the soil nutrition and amendment materials (April 15, 2009), the tree height (HT) and diameter at breast height (DBH) were measured for each experimental tree. A conventional downward tapping method (CFA, 2007; Chen \& Li, 2009) was employed, which was commonly practiced in the production of oleoresin in the South China. By following the local oleoresin production practice, the tapping was started on May 29, 2009, and after that, repeated every day for P. massoniana and every 2 days for P. elliottii until Nov 30, 2009. The oleoresin was collected and weighted for each tree 3 times, on Jun $29\left(\mathrm{RY}_{1}\right)$, Sept $17\left(\mathrm{RY}_{2}\right)$ and Dec 5, 2009 $\left(\mathrm{RY}_{3}\right)$, respectively. On Dec 20, 2009, all trees were measured for HT and DBH again as well as the average tapping width $\left(\mathrm{T}_{\mathrm{W}}\right)$ and length $\left(\mathrm{T}_{\mathrm{L}}\right)$.

\subsection{Statistical Analysis}

The increments in diameter at breast height and tree height, denoted by $\mathrm{D}_{\mathrm{DBH}}$ and $\mathrm{D}_{\mathrm{HT}}$, were calculated with two tree growth measurements. Besides $\mathrm{D}_{\mathrm{DBH}}, \mathrm{D}_{\mathrm{HT}}, \mathrm{RY}_{1}, \mathrm{RY}_{2}$ and $\mathrm{RY} \mathrm{Y}_{3}$, two more oleoresin yield indicators were obtained for statistical analysis: 1) the total yield $\left(\mathrm{RY}_{\mathrm{T}}\right)=\mathrm{RY}_{1}+\mathrm{RY} \mathrm{Y}_{2}+\mathrm{RY} \mathrm{Y}_{3}$, and 2) the yield per $\mathrm{cm}^{2}$ of tapping area $\left(R Y_{A}\right)=R Y_{T} /\left(T_{W} \times T_{L}\right)$. For each species, SAS GLM (SAS Institute Inc., 1992) was run, 1) to analyze the effects of block (replicate) and soil treatment scheme (ANOVAs), 2) to calculate the least-squared means of 9 soil treatment schemes, and the averages of the least-squared means for each treatment material and dosage, and 3) to test significance of effect of four treatment materials applied. 
Table 2. Nine soil treatment schemes and their compositions of 4 materials.

\begin{tabular}{|c|c|}
\hline Scheme Code & Combinations of 4 treatment materials \\
\hline $\mathrm{T} 1$ (control) & $\mathrm{W}(0 \mathrm{~g} /$ tree $)+\mathrm{C}$ (0 g/tree $)+\mathrm{L}$ (0 g/tree $)+\mathrm{B}(0 \mathrm{~g} /$ tree $)$ \\
\hline $\mathrm{T} 2$ & W (0 g/tree) + C (250 g/tree ) + L (100 g/tree) + B (7.5 g/tree) \\
\hline T3 & W (0 g/tree) + C (500 g/tree ) + L (200 g/tree) + B (15 g/tree) \\
\hline $\mathrm{T} 4$ & W (10 g/tree ) + C (0 g/tree ) + L (100 g/tree $)+$ B (15 g/tree $)$ \\
\hline T5 & W (10 g/tree $)+$ C (250 g/tree ) + L (200 g/tree $)+$ B (0 g/tree) \\
\hline T6 & W (10 g/tree) + C (500 g/tree ) + L (0 g/tree) + B (7.5 g/tree) \\
\hline $\mathrm{T} 7$ & W (20 g/tree) + C (0 g/tree ) + L (200 g/tree) + B (7.5 g/tree) \\
\hline $\mathrm{T} 8$ & W (20 g/tree) + C (250 g/tree ) + L (0 g/tree) + B (15 g/tree) \\
\hline T9 & W (20 g/tree $)+$ C (500 g/tree ) + L (100 g/tree $)+$ B (0 g/tree) \\
\hline
\end{tabular}

\section{Results and Discussion}

\subsection{ANOVAs}

The results of ANOVAs were presented in Table 3 for both species. In slash pine, two blocks or replicates (R) of the experiment significantly or nearly significantly differed in the oleoresin yield $\left(R Y_{1}, R_{2}, R Y_{3}, R Y_{T}\right.$ and $\left.\mathrm{RY}_{\mathrm{A}}, 0.01<P<0.07\right)$ but not in tree growth traits $\left(\mathrm{D}_{\mathrm{DBH}}\right.$ and $\left.\mathrm{D}_{\mathrm{HT}}\right)$. Soil treatment scheme $(\mathrm{T})$ significantly affected $\mathrm{RY}_{\mathrm{T}}(P=0.043)$ and $\mathrm{RY}_{\mathrm{A}}(P=0.02)$, but not other oleoresin yield indicators and tree growth traits (Table 3). Although the effect of soil treatment scheme on $\mathrm{RY}_{1}, \mathrm{RY}_{2}$ and $\mathrm{RY}_{3}$ was not statistically significant, but tended to become stronger over time. The difference in the micro-environmental conditions of two blocks was mainly characterized by their soil properties, and, therefore, the significant block effect indirectly strengthened the role of soil treatment scheme in oleoresin production of mature or near-mature trees. In masson pine, block and soil treatment scheme did not generate any significant effect on the growth and oleoresin yield of trees. Both pine species did not respond well in growth to the soil conditions or soil treatment as young or medium age trees (Shu et al., 2009), probably because the mature or near-mature trees normally grew little, and the oleoresin tapping further stunted growth (Chen \& Li, 2009). In terms of oleoresin yield, slash pine was more sensitive to soil treatment than masson pine, implying that the later was more adaptive to extremely acidic soil environment.

\subsection{Ranking of Four Treatment Materials}

Four soil treatment materials were ranked for their separate effects with their statistical significance on oleoresin yield traits for each species (Table 4). In slash pine, it appeared that lime (L) played the most important and exclusively significant role in oleoresin production, followed by compound fertilizer (C) or water retainer (W) (Table 4). The roles of $\mathrm{C}$ and $\mathrm{W}$ along with $\mathrm{B}$ were inconsistent and not statistically significant, and might be negligible. In masson pine, the roles of all four materials were confusing, but lime, water retainer and compound fertilizer played some marginal roles in oleoresin yield. In particular, lime significantly affected $\mathrm{RY}_{\mathrm{A}}(P<0.05)$, which was not consistent with the general role of soil treatment in this native species (Table 3).

Oleoresin yield is closely related to DBH and tapping intensity (Liu et al., 2007; Rodrigues et al., 2008; Rodríguez-García et al., 2014). $\mathrm{RY}_{\mathrm{A}}$ was not related to tree size and tapping area, and could be seen as a better indicator of oleoresin yield. The role of lime in this indicator seemed consistently largest in both species. Because soils were extremely acid for both species (Table 1), it was believed that application of lime improved the soil or increased the $\mathrm{pH}$ value of soil to a status that might be favorable for oleoresin production. Lime might have other potential roles in oleoresin yield, for example, the presence of calcium and manganese, or the improved bioavailability of mineral nutrients for plant root and mycorrhizae absorption upon $\mathrm{pH}$ correction. The present study, however, did not further investigate these potential roles.

It was surprising however that fertilizer did not exhibit a significant role although soil nutrition status was poor (Table 1), as suggested for young or medium age pine trees in few recent studies (Warren et al., 1999; Knebel et al., 2008; Xie, 2008; An et al., 2010; Novick et al., 2012). Water retainer did not work well probably because the annual rainfall was high $(1580 \mathrm{~mm}$, similar to the historic mean value), with $85 \%$ distributed during 
Table 3. ANOVAs (P-value) for block and soil treatment effects on tree growth and oleoresin production traits.

\begin{tabular}{cccccccccc}
\hline Species & Source & $\mathrm{df}$ & $\mathrm{D}_{\mathrm{DBH}}$ & $\mathrm{D}_{\mathrm{HT}}$ & $\mathrm{RY}_{1}$ & $\mathrm{RY}_{2}$ & $\mathrm{RY}_{3}$ & $\mathrm{RY}_{\mathrm{T}}$ & $\mathrm{RY}_{\mathrm{A}}$ \\
\hline \multirow{2}{*}{ Slash pine } & $\mathrm{R}$ & 1 & 0.303 & 0.964 & 0.039 & 0.026 & 0.035 & 0.011 & 0.069 \\
& $\mathrm{~T}$ & 8 & 0.739 & 0.342 & 0.313 & 0.199 & 0.105 & 0.043 & 0.020 \\
\multirow{2}{*}{ Masson pine } & $\mathrm{R}$ & 1 & 0.358 & 0.807 & 0.227 & 0.340 & 0.241 & 0.137 & 0.315 \\
& $\mathrm{~T}$ & 8 & 0.480 & 0.799 & 0.559 & 0.921 & 0.603 & 0.795 & 0.275 \\
\hline
\end{tabular}

Table 4. Ranking and significant test of four soil nutrition materials in oleoresin yield.

\begin{tabular}{|c|c|c|c|c|c|c|}
\hline Species & Rank & $\mathrm{RY}_{1}$ & $\mathrm{RY}_{2}$ & $\mathrm{RY}_{3}$ & $\mathrm{RY}_{\mathrm{T}}$ & $\mathrm{RY}_{\mathrm{A}}$ \\
\hline \multirow{4}{*}{ Slash pine } & 1 & $\mathrm{~L}$ & C & $\mathrm{L}^{*}$ & $\mathrm{~L}^{*}$ & $\mathrm{~L}^{* *}$ \\
\hline & 2 & W & $\mathrm{W}$ & $\mathrm{C}$ & $\mathrm{C}$ & W \\
\hline & 3 & $\mathrm{C}$ & L & B & B & B \\
\hline & 4 & B & B & W & $\mathrm{W}$ & $\mathrm{C}$ \\
\hline \multirow{4}{*}{ Masson pine } & 1 & $\mathrm{~W}$ & $\mathrm{~W}$ & B & $\mathrm{W}$ & $\mathrm{L}^{*}$ \\
\hline & 2 & $\mathrm{C}$ & $\mathrm{C}$ & $\mathrm{C}$ & $\mathrm{C}$ & W \\
\hline & 3 & $\mathrm{~L}$ & $\mathrm{~L}$ & $\mathrm{~L}$ & B & $\mathrm{C}$ \\
\hline & 4 & B & B & W & $\mathrm{L}$ & B \\
\hline
\end{tabular}

Note: ${ }^{*}$ significant effect at level of $P<0.05 ;{ }^{* *}$ effect significant at level of $P<0.01$.

the experimental period in the region. Extra nutrition B, which was supplied from application of borax, was a useful micro-element for trees, but did not help stimulate the oleoresin yield either.

\subsection{Effect of Dosage}

The effect of lime dosage on oleoresin yield was only presented for oleoresin traits with significant difference in both pine species (Table 5). It was clear that slash pine oleoresin yield significantly increased as lime was applied and the dosage was increased. The difference between lime dosages of $0 \mathrm{~g} /$ tree and $100 \mathrm{~g} /$ tree was significant at level of $P<0.05$, and the difference between lime dosages of $0 \mathrm{~g} /$ tree and $200 \mathrm{~g} /$ tree was even more significant $(P<0.01)$ as expected. However, the difference was not significant when lime dosage was increased from $100 \mathrm{~g} /$ tree to $200 \mathrm{~g} /$ tree $(P>0.05)$. Effective lime dosage for slash pine should therefore be more than 100 $\mathrm{g} /$ tree. Masson pine oleoresin yield markedly increased as lime dosage increased to $100 \mathrm{~g}$ /tree from $0 \mathrm{~g} /$ tree $(P<$ $0.01)$, but decreased insignificantly $(P>0.05)$ when lime dosage further increased to $200 \mathrm{~g} /$ tree. Therefore, there was an optimal lime dosage for high oleoresin yield of masson pine.

Both species are adapted to acidic soils (Chen \& Li, 2009). Masson pine was naturally distributed over more acidic soils than slash pine. It may therefore be reasoned that masson pine is more adapted to soils of strong acidity than slash pine. This might also explain the results and difference of two species in response to application of lime in the present study, that is, slash pine was more sensitive to use of lime than masson pine in poorly acidified forest sites.

\subsection{Effective Scheme}

We compared effective schemes in terms of $\mathrm{RY}_{\mathrm{A}}$. For slash pine, the best scheme was T7, followed by T9 and $\mathrm{T} 5$ (Table 2). The average of T7, T9 and T5 could be considered as the effect of lime, and removal of effects of insignificant materials W, C and B. Lime effect $\left(4.56 \mathrm{~g} / \mathrm{cm}^{2}\right)$ at the treatment dosage of $167 \mathrm{~g} /$ tree generated a gain of $16.6 \%$ and $43.7 \%$ compared to the mean $\left(3.91 \mathrm{~g} / \mathrm{cm}^{2}\right)$ of all nine treatment schemes and the treatment with minimum oleoresin yield $\left(3.17 \mathrm{~g} / \mathrm{cm}^{2}\right)$, respectively. For masson pine, the best scheme was $\mathrm{T} 4$, followed by T9 and T5 (Table 2). Lime effect $\left(3.52 \mathrm{~g} / \mathrm{cm}^{2}\right)$ at the treatment dosage of $133 \mathrm{~g} /$ tree generated $18.3 \%$ and $37.4 \%$ more yield compared to the mean $\left(2.97 \mathrm{~g} / \mathrm{cm}^{2}\right)$ of all nine treatments and the treatment with minimum oleoresin yield $\left(2.56 \mathrm{~g} / \mathrm{cm}^{2}\right)$, respectively. In general, a range of $15 \%$ to $35 \%$ of gain in oleoresin yield resulting from lime 
Table 5. Pair comparison of lime dosage per tree in oleoresin yield of both species.

\begin{tabular}{|c|c|c|c|c|c|c|c|}
\hline Species & Dosage (g) & $\mathrm{RY}_{3}$ & & $\mathrm{RY}_{\mathrm{T}}$ & & $\mathrm{RY}_{\mathrm{A}}$ & \\
\hline \multirow{3}{*}{ Slash pine } & 0 & 448.5 & & 1548.7 & & 3.303 & \\
\hline & 100 & 566.8 & $*$ & 1827.9 & $*$ & 4.042 & $*$ \\
\hline & 200 & 587.5 & $*$, ns & 1909.8 & $* *$, ns & 4.366 & **, ns \\
\hline \multirow{3}{*}{ Masson pine } & 0 & & & & & 2.57 & \\
\hline & 100 & & & & & 3.52 & $* *$ \\
\hline & 200 & & & & & 2.85 & ns, ns \\
\hline
\end{tabular}

Note: ns, non-significant; *, significant at level of $P<0.05$; **, significant at level of $P<0.01$.

use in extremely acid soils may be reasonable and conservative for both species in the South China.

\subsection{Prospects and Limitations}

Pine oleoresin yield could significantly be increased by use of improved planting material (McReynolds, 1971; Lu et al., 1992; Roberds \& Strom, 2006) and tapping stimulant (Liu \& Zhu, 2003; Chen, 2004; Rodrigues et al., 2008; Chen \& Li, 2009). While development of improved planting material is accepted as a long-term strategy, use of tapping stimulant is well applauded for short-term benefit from existing mature stands. However, the former takes time and the later may lead to some negative issues such as exhausting resin extraction early or shortened tapping viability although no strong data or evidence proves so. Soil or site nutrition management sounds a natural concept for stands or trees tapped for high oleoresin probably with less or no negative issues. This concept may adjust soil or site to a better nutrition status, not only currently improving oleoresin yield but also probably maintaining long productivity (Lorio \& Sommers, 1986; Rigling et al., 2003).

Although fertilizer, water retainer and borax did not significantly affect the oleoresin yield in this study, several reasons require that more efforts be contributed to the studies in this area. First, pine oleoresin is a traditional forest by-product, and the market price has sharply been increased in the last decade because of the increased market demand but drastically reduced pine resources for oleoresin tapping in the South China, one of the most important production regions (Chen \& Li, 2009). Second, little or inconsistent knowledge in terms of the relationship between soil nutrition status and pine oleoresin yield is available (Lorio \& Sommers, 1986; Warren et al., 1999; Rigling et al., 2003; Knebel et al., 2008; Xie, 2008; Shu et al., 2009; An et al., 2010; Novick et al., 2012). It is worthy to explore any possibility to increase oleoresin production from existing pine resources. The significant effect of lime, regardless of its direct or indirect roles, implied that soil nutrition status, particularly when poorly deviant from a normal condition such as in the present case (Table 1), could be properly adjusted to stimulate the production of pine oleoresin yield (Lorio \& Sommers, 1986; Rigling et al., 2003; Xie, 2008; An et al., 2010; Novick et al., 2012). Finally, the present experiment was one-year and relatively small scale. Small samples of trees might incur large errors, masking some useful conclusions. More and systematic experiments are certainly necessary to make better and accurate conclusions.

Lime for soil treatment was generally cheap, with resale price of about US $\$ 55 /$ ton. The cost of lime was US $\$ 9.7$ per hectare, but the labor was much more expensive, charging about US \$118/ha. Nevertheless, it was highly profitable if the current price of oleoresin (US \$1886 - \$2672) was considered. This is a strong motivation for us to further study and apply soil nutrition management in pine stands for tapping oleoresin. When soil nutrition management cost is high (more expensive labor and material such as water retainer, fertilizer and borax), and oleoresin becomes cheaper, the economic benefit would lower correspondently.

\section{Conclusion}

Application of lime to soils with low acidity ( $\mathrm{pH}$ value $\leq 4.0$ ) was effective in significantly increasing annual oleoresin production of pines. The principle was probably to adjust soil or site conditions to a better status that favored secretion of pine oleoresin. The roles of other soil treatment materials tested were not observable. Cheap lime would become a useful material to amend the vast forestlands with heavy acid deposition and degradation, improving not only the oleoresin production but also forest environment and immature tree growth. The effec- 
tive amount of lime for high yield depended on the species as well as soil acidifying level. Proper application of lime could result in high and justified economic benefit from tapping mature or near-mature pine plantations for oleoresin. The findings in this study may be applicable to wide-distributed pine plantations with acidified soils in the South China. Soil or site nutrition management seems to be a promising concept in terms of use of existing resources, stand health and wood quality, and sustainable productivity for high oleoresin yield. However, extension of this concept including lime and other potential alternatives requires more and systematic experiments and investigations.

\section{Acknowledgements}

The present study was part of China Spark Program Project "Research and Application of Integrated Technologies on Cultivation of Pine Plantations for High Wood and Oleoresin Production and Utilization of Rosin Products”. The field experiment was completed with assistance of Jianhang Xu, Guoxian Chen, Wei Li and Yanqing Wang.

\section{References}

An, N., Ding, G., \& Chen, H. (2010). Effect of Stand Density and Fertilization on Resin Yield of Pinus massoniana. Journal of Central-South Forestry and Technology University, 30, 46-50.

Chen, J. (2004). Effect of Reagent Application on Pine Oleoresin. Fujian Forestry Science and Technology, 31, 38-41.

Chen, D., \& Li, C. (2009). Techniques for Producing Pine Oleoresin in China. Beijing: China Forestry Publishing House.

China Forestry Administration (CFA) (2007). The Technical Regulations of Resin Tapping. Beijing: PRC Forestry Industrial Standard (LY/T 1694-2007).

Coppen, J. J. W., \& Hone, G. A. (1995). Gum Naval Stores: Turpentine and Rosin from Pine Resin, Non-Wood Forest Products 2. Rome: Natural Resources Institute, FAO.

Knebel, L., Robison, D. J., Wentworth, T. R., \& Klepzig, K. D. (2008). Resin Flow Responses to Fertilization, Wounding and Fungal Inoculation in Loblolly Pine (Pinus taeda) in North Carolina. Tree Physiology, 28, 847-853. http://dx.doi.org/10.1093/treephys/28.6.847

Li, Z.-A., Zou, B., Cao, Y.-S., Ren, H., \& Liu, J. (2003). Nutrient Properties of Soils in Typical Degraded Hilly Land in South China. Acta Ecologica Sinica, 23, 1648-1656.

Liu, D., Gao, Z., Peng, Z., Zeng, G., Zheng, X., \& Wu, M. (2007). Research on the Techniques of Resin Tapping of Pinus elliottii. Jiangxi Forestry Science and Technology, 2, 7-11.

Liu, F.-P. (2007). Forest Soil Acidification Status Analysis and Control Measures in Guangdong Province. Forest Inventory and Planning, 32, 69-71.

Liu, H., \& Zhu, Y. (2003). Application of Oleoresin Stimulants in Slash Pine Tapping. Hunan Forestry Science and Technology, 30, 68-69.

Liu, Z., Zhu, Q.-Q., Tang, L.-H., Xu, J.-X., \& Yen, C.-L. (1982). Geographic Distribution of Trace Elements-Deficient Soils in China. Acta Pedologica Sinica, 19, 209-223.

Lorio Jr., P. L., \& Sommers, R. A. (1986). Evidence of Competition for Photosynthates between Growth Processes and Oleoresin Synthesis in Pinus taeda L. Tree Physiology, 2, 301-306. http://dx.doi.org/10.1093/treephys/2.1-2-3.301

Lu, P., Pan, Z., Wang, Y., \& Feng, Y. (1992). Variation of Oleoresin Yield among High-Gum Yielding Slash Pine Families and Their Realized Genetic Gain. Forest Research, 5, 700-705.

McReynolds, R. D. (1971). Heritability and Seasonal Changes in Viscosity of Slash Pine Oleoresin. USDA Forest Service Research Note SE-155, Asheville, NC: Southeastern Forest Experiment Station, Forest Service, US Department of Agriculture.

National Soil Survey Office (NSSO) (1992). Techniques for Surveying Soil in China. Beijing: Agricultural Publishing House.

Novick, K. A., Katul, G. G., McCarthy, H. R., \& Oren, R. (2012). Increased Resin Flow in Mature Pine Trees Growing under Elevated $\mathrm{CO}_{2}$ and Moderate Soil Fertility. Tree Physiology, 32, 752-763. http://dx.doi.org/10.1093/treephys/tpr133

Rigling, A., Brühlhart, H., Bräker, O. U., Forster, T., \& Schweingruber, F. H. (2003). Effects of Irrigation on Diameter Growth and Vertical Resin Duct Production in Pinus sylvestris L on Dry Sites in the Central Alps, Switzerland. Forest Ecology and Management, 175, 285-296. http://dx.doi.org/10.1016/s0378-1127(02)00136-6

Rodrigues, K. C. S., Azevedo, P. C. N., Sobreiro, L. E., Pelissari, P., \& Fett-Neto, A. G. (2008). Oleoresin Yield of Pinus elliottii Plantations in a Subtropical Climate: Effect of Tree Diameter, Wound Shape and Concentration of Active Adjuvants 
in Resin Stimulating Paste. Industrial Crops and Products, 27, 322-327. http://dx.doi.org/10.1016/j.indcrop.2007.11.010

Rodríguez-García, A., Rosana López, R., Martín, J. A., Pinillos, F., \& Gil, L. (2014). Resin Yield in Pinus pinaster Is Related to Tree Dendrometry, Stand Density and Tapping-Induced Systemic Changes in Xylem Anatomy. Forest Ecology and Management, 313, 47-54. http://dx.doi.org/10.1016/j.foreco.2013.10.038

Roberds, J. H., \& Strom, B. L. (2006). Repeatability Estimates for Oleoresin Yield Measurements in Three Species of the Southern Pines. Forest Ecology and Management, 228, 215-224. http://dx.doi.org/10.1016/j.foreco.2006.03.005

SAS Institute Inc. (1992). SAS/STAT User's Guide. Cary, NC: SAS Campus Drive.

Shu, W., Yang, Z., \& Lan, F. (2009). Effects of Fertilization on the Growth and Resin Yield of Middle-Aged Forest of Pinus massoniana. Journal of Fujian Forestry College, 29, 160-165.

Song, Z. (1998). Characteristics of Oleoresin and Classification of Pinus in China. Beijing: China Forestry Publishing House.

Warren, J. M., Allen, H. L., \& Brooker, F. L. (1999). Mineral Nutrition, Resin Flow and Phloem Phytochemistry in Loblolly Pine. Tree Physiology, 19, 655-663. http://dx.doi.org/10.1093/treephys/19.10.655

Wei, R.-P. (1990). Introduction, Silviculture and Management of Slash Pine over the Whole World. World Forestry Research, 3, 56-61.

Xie, S. (2008). Fertilizer Effects on the Resin Production of Low-Yield-Resin Plantations of Pinus massoniana. Fujian Forestry Science and Technology, 35, 34-36.

Zhou, X., \& Qin, W. (1992). Sensitivity of the Soil in South China to Acid Deposition. Acta Scientiae Circumstantiae, 12, 78-83. 
Scientific Research Publishing (SCIRP) is one of the largest Open Access journal publishers. It is currently publishing more than 200 open access, online, peer-reviewed journals covering a wide range of academic disciplines. SCIRP serves the worldwide academic communities and contributes to the progress and application of science with its publication.

Other selected journals from SCIRP are listed as below. Submit your manuscript to us via either submit@scirp.org or Online Submission Portal.
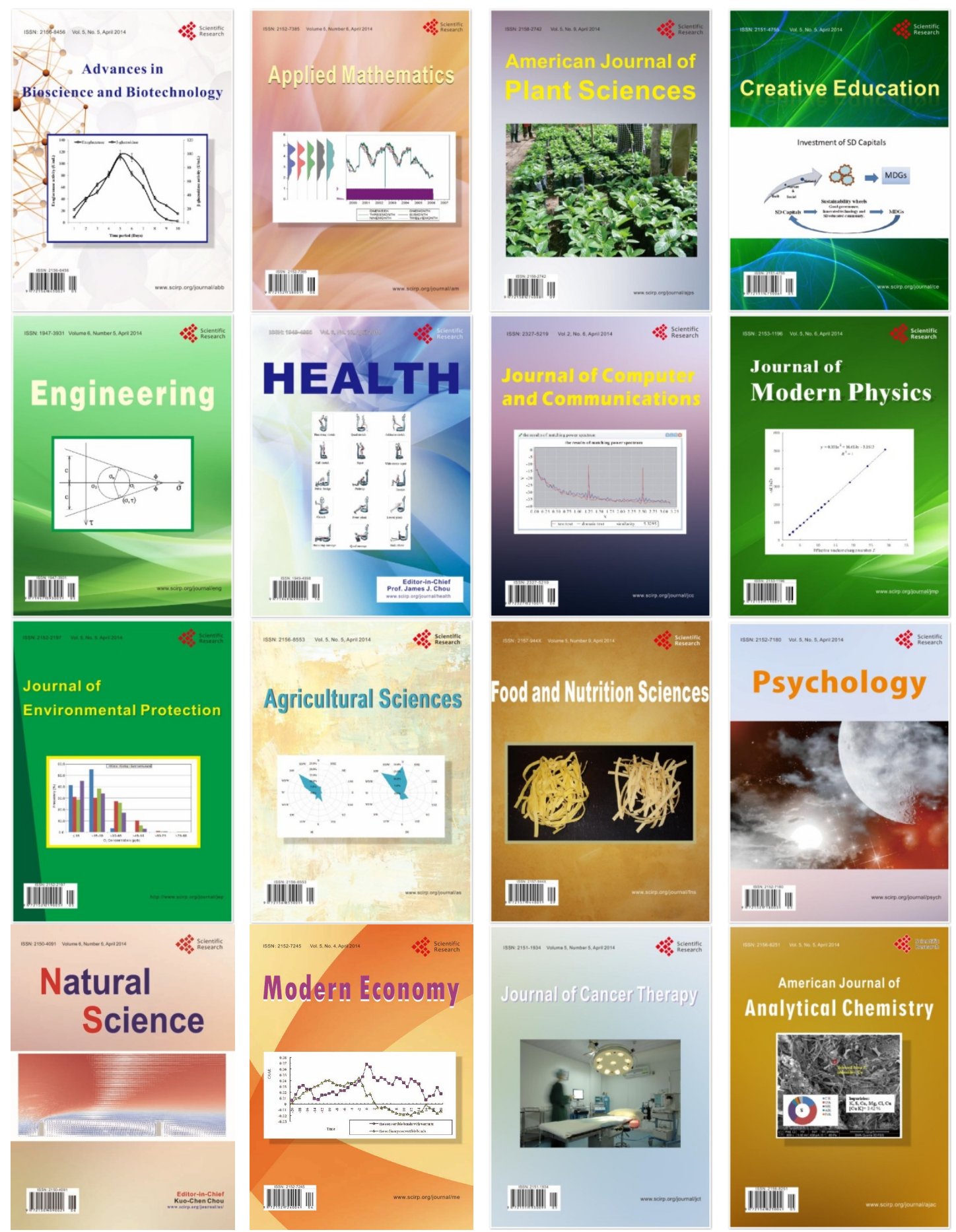